\title{
EVOLUÇÃO ESPAÇO-TEMPORAL DO USO E COBERTURA DA TERRA NA BACIA DO RIO PURAQUEQUARA (MANAUS-AM)
}

\author{
Renato Kennedy Ribeiro Neves \\ Universidade do Estado do Amazonas, Mestre em Gestão e Regulação de Recursos Hídricos, Amazonas, Brasil \\ rkennedy.neves@gmail.com
}

leda Hortêncio Batista
Universidade do Estado do Amazonas, Docente do Programa de Pós-Gradução em Gestão e Regulação de
Recursos Hídricos (ProfÁgua), Amazonas, Brasil
iedahbatista@gmail.com

José Roselito Carmelo da Silva

Instituto Federal de Educação, Ciência e Tecnologia do Amazonas, Docente do Departamento de Química, Ambiente e Alimentos, Amazonas, Brasil jroselito@uol.com.br

Elton Alves de Souza Filho Universidade do Estado do Amazonas, Mestre em Gestão e Regulação de Recursos Hídricos, Amazonas, Brasil easf891@gmail.com

Eduardo Papi Lemos das Neves Universidade Federal do Amazonas, Graduado em Geografia, Amazonas, Brasil eduardo.geo2011@gmail.com

\begin{abstract}
RESUMO
O objetivo do trabalho foi realizar a análise da evolução espaço-temporal, nos anos de 2005, 2010 e 2016, do uso e cobertura da terra na bacia do Rio Puraquequara, localizada no município de Manaus (AM). Foram adquiridos dados junto ao Instituto Nacional de Pesquisas Espaciais (INPE) e do Instituto Brasileiro de Geografia e Estatísticas (IBGE). O processamento dos dados cartográficos foi realizado no ambiente do Sistema de Informações Geográficas (SIG). Para mapeamento das classes, foi utilizada a classificação não supervisionada, que é feita por meio do processamento automático de geração de classes. O cálculo da área de cada uma das classes foi realizado com o auxílio do algoritmo calculate geometry. Os resultados demostraram que há predominância da classe de vegetação primária $(78,78 \%)$, porém, na margem direita, a classe de solo exposto $(11,23 \%)$ e mancha urbana $(1,23 \%)$ continuam avançando sobre áreas de vegetação nativa e secundária. Portanto, é necessária mais atenção dos órgãos de fiscalização, principalmente, para delimitação da Área de Preservação Permanente (APP) dos igarapés que desaguam no Rio Puraquequara.
\end{abstract}

Palavras-chave: Bacia hidrográfica. Igarapé. Mancha urbana.

\section{SPACE-TIME EVOLUTION OF LAND USE AND COVERAGE IN THE PURAQUEQUARA RIVER BASIN (MANAUS-AM)}

\begin{abstract}
The aim of this work was to perform an analysis of spatiotemporal evolution, in 2005, 2010 and 2016, to use and cover the surface of the Puraquequara River basin, Manaus (AM). Data were obtained from the National Institute for Space Research (INPE) and the Brazilian Institute of Geography and Statistics (IBGE). The cartographic data processing was performed in the Geographic Information System (GIS) environment. For class mapping, we used an Unsupervised Classification that is done through automatic class processing. The calculation of the area of each of the classes was performed with the aid of the geometry calculation algorithm. The results show that there is a predominance of tropical vegetation class $(78.78 \%)$, but on the right bank, an exposed soil class $(11.23 \%)$ and urban patch $(1.23 \%)$ continue to advance over vegetation areas. native and secondary. Therefore, the attention of the inspection agencies is more necessary, especially for delimitation of the Permanent Protection Area (APP) of streams that flow into the Puraquequara River.
\end{abstract}

Keywords: Hydrographic basin. Igarapé. Urban spot.

$\begin{array}{llllll}\text { Caminhos de Geografia } & \text { Uberlândia - MG } & \text { v. 21, n. } 73 & \text { Mar/2020 } & \text { p. 347-355 } & \text { Página } 347\end{array}$




\section{INTRODUÇÃO}

Os recursos hídricos são vitais para preservação e conservação da vida na Terra. O desenvolvimento das sociedades e 0 crescimento das atividades industriais e agrícolas dependem da qualidade e quantidade de água disponível nas regiões hidrográficas. No Brasil, a Lei Federal 9.433/1997 instituiu a Política Nacional de Recursos Hídricos (PNRH) e tem como principais fundamentos a gestão múltipla das águas e a bacia hidrográfica como unidade territorial de implementação da PNRH.

A bacia hidrográfica é considerada objeto de estudo para inúmeros pesquisadores da Geografia e das Ciências Ambientais. O levantamento de dados topográficos, a análise da qualidade da água, as mudanças espaço-temporais, o potencial erosivo e a gestão de recursos hídricos formam um conjunto de indicadores que possibilita a avaliação sistêmica da dinâmica dos componentes ambientais em sua área de abrangência (SOARES, 2016).

$\mathrm{Na}$ visão de Albuquerque (2012), o uso das bacias hidrográficas como unidades espaciais está associado a três parâmetros: caracterização de espaço físico, através da delimitação da área e do reconhecimento do ambiente; organização espacial, agindo como célula de análise integrada; e, por fim, gestão, por meio da aplicabilidade de legislação específica.

A avaliação do ambiente integrado de uma bacia hidrográfica varia conforme a relação entre os aspectos naturais e os grupos sociais. A qualidade da água dos rios que a compõe está relacionada ao uso do solo e ao grau de controle sobre as fontes de poluição existentes na bacia (BOTELHO, 2011).

As análises históricas da dinâmica do Uso e Cobertura da Terra (UCT) são necessárias para o conhecimento das alterações espaciais motivadas pelo desmatamento, ocupações irregulares ou por atividades econômicas que degradam os recursos hídricos. O uso de imagens geradas pelo Sensoriamento Remoto (SR), aliado ao uso do Sistema de Informações Geográficas (SIG) geram dados substanciais para planejamento territorial e ambiental.

$\mathrm{Na}$ cidade de Manaus, capital do Estado do Amazonas, destacam-se as bacias do Tarumã, São Raimundo, Educandos e Puraquequara (MIRANDA, 2017). Devido ao processo de urbanização impulsionado pelo Polo Industrial de Manaus (PIM), a região adquiriu inúmeros problemas ambientais, entre eles diversas ocupações irregulares em ambientes naturais, incisões erosivas em áreas de risco, supressão de áreas verdes e a poluição por esgoto doméstico dos igarapés.

O crescimento expoente de sua população em função do PIM resultou na expansão urbana, principalmente nas zonas administrativas Norte e Leste, intensificando problemas urbanos já vistos na zona Sul da parte histórica da cidade, como a falta de saneamento básico, poluição dos igarapés, lixeiras viciadas e a ocupação de vertentes. Segundo Silva (2016, p. 39), "sem estrutura econômica e social, a população foi ocupando no centro da cidade os locais que não interessavam aos setores da classe média como os vales dos igarapés, áreas íngremes sujeitas a deslizamentos e moradias embaixo das pontes [...]".

Pesquisas recentes desenvolvidas por Miranda (2017) apontam alterações espaciais do uso e cobertura da terra na porção sudeste da bacia do Rio Puraquequara. A conversão de áreas verdes em aglomerados subnormais estão evidentes nos bairros adjacentes. Nesse sentido, cabe uma avaliação por meio das imagens de satélites em conjunto com o SIG para análise da dinâmica da espacial da bacia.

Assim, a pesquisa objetivou analisar a evolução espaço-temporal do Uso e Ocupação da Terra por meio das geotecnologias, buscando gerar resultados que contribuam para gestão dos recursos naturais e o planejamento urbano da área de estudo. Portanto, os inúmeros conflitos existentes pela pressão do uso e ocupação do solo sem planejamento adequado, devido principalmente à ínfima atuação do Poder Público para minimizar a problemática socioambiental, são situações que motivaram a pesquisa, vislumbrando contribuir, conforme orientado pelo $\mathrm{PNRH}$, com uma gestão compartilhada no uso múltiplos na área da bacia hidrográfica com vista ao desenvolvimento sustentável do local. 


\section{MATERIAIS E MÉTODOS}

\section{ÁREA DE ESTUDO}

O estudo foi desenvolvido na bacia hidrográfica do Rio Puraquequara, localizada no extremo Leste do município de Manaus (figura 1). Segundo Costa et al, (2013), a bacia possui uma área de 694,834 $\mathrm{Km}^{2}$ e seu espaço territorial alcança os limites urbanos da cidade de Manaus, tendo como adjacência a zona administrativa Leste, representada pelos bairros Jorge Teixeira, Distrito Industrial e Puraquequara.

A área de estudo está assentada sobre o platô da Formação Alter do Chão, composta por sedimentos avermelhados com predominância de argilas, sites, arenitos e conglomerados (PEQUENO FILHO, 2015). De acordo com Projeto Geo Cidades (2002), o curso principal da bacia hidrográfica é o Rio Puraquequara, afluente da margem esquerda do Rio Amazonas, e tem como os principais afluentes os igarapés, do Boa Vista, Água Branca, Mainanzinho, Mainá, além do Lago do Puraquequara.

A bacia apresenta grande predominância de vegetação de Floresta Amazônica na sua porção oriental, devido principalmente às bases de treinamento do Exército Brasileiro. Na porção ocidental, há uma forte redução de floresta nativa por conta do espraiamento da franja urbana causado pela conversão de floresta primária em áreas urbanas e de produção agrícola.

\section{DADOS}

A primeira etapa do trabalho foi a aquisição de dados cartográficos do Instituto Brasileiro de Geografia e Estatística (IBGE, 2010) e do Instituto de Nacional de Pesquisas Espaciais (INPE, 2016) em formato digital. Para construção do banco de dados cartográficos e a elaboração dos mapas temáticos, foram utilizados os seguintes arquivos:

- Imagem do sensor Themattic Mapper - TM do satélite Landsat 5, com resolução espacial de 30 metros, bandas espectrais $3,4,5$, referentes ao vermelho $(0,63-0,69 \mu \mathrm{s})$, infravermelho próximo $(0,76-0,90 \mu \mathrm{s})$ e infravermelho médio $(1,55-1,75 \mu \mathrm{s})$;

- Imagem do sensor OLI Landsat 8, com resolução espacial de 30 metros, bandas espectrais 4,5 e 6 e 15 metros para banda pancromática;

- As cenas são referentes às orbitas 230 e 231, ponto 062: 24 de setembro de 2005; 27 de julho de 2010; 20 de setembro de 2016;

- Base vetorial do município de Manaus, contendo perímetro urbano, zonas administrativas, hidrografia, curvas de nível e arruamento, em formato shappefile, referente ao ano de 2010;

- Programa Arcgis 10.2, da ESRI (Environmental Systems Research Institute), versão demo.

Figura 1- Mapa de localização da Bacia do Rio Puraquequara, Manaus/Amazonas

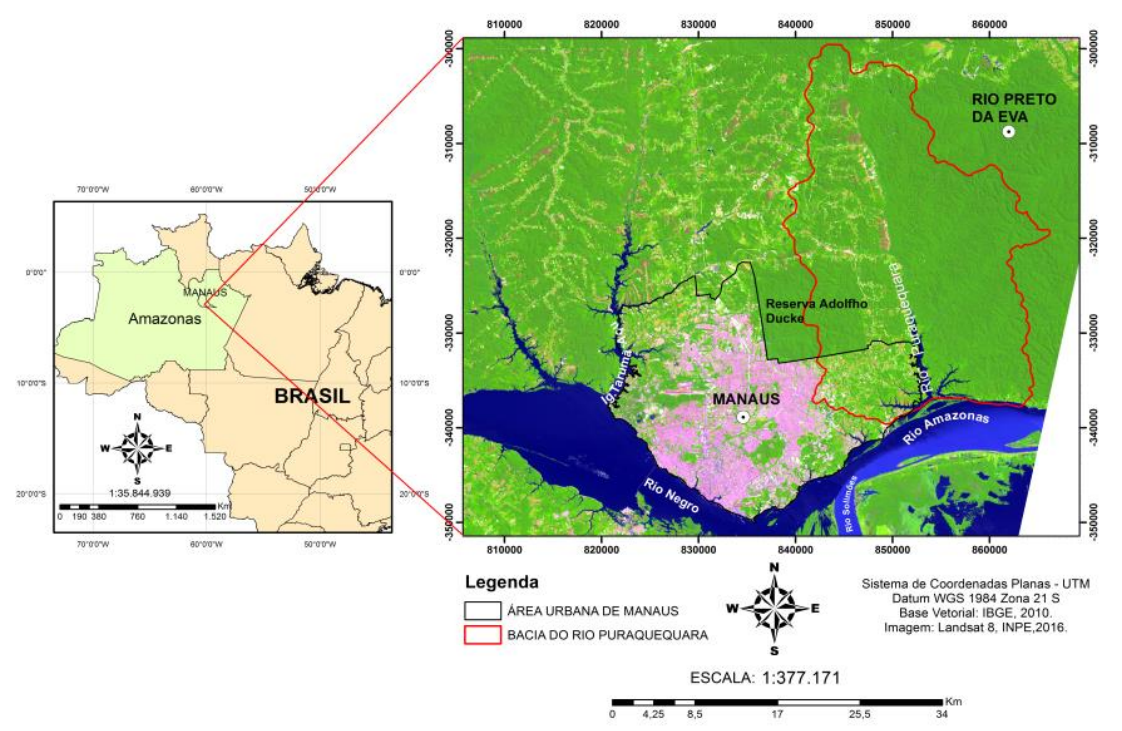

Fonte - Autores, 2018

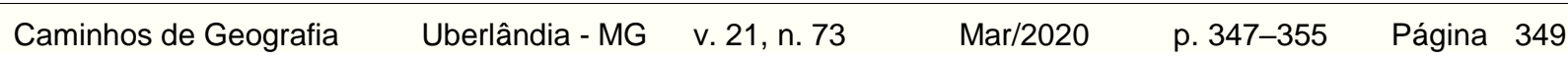


Evolução espaço-temporal do uso e cobertura da terra na Bacia do rio Puraquequara (Manaus-AM)
Renato Kennedy Ribeiro Neves leda Hortêncio Batista José Roselito Carmelo da Silva Elton Alves de Souza Filho

Eduardo Papi Lemos das Neves

\section{PROCESSAMENTO DAS IMAGENS DE SATÉLITE E CLASSIFICAÇÃO DO USO E COBERTURA DA TERRA}

Por meio do SIG, mais especificamente o Arcgis 10.2, as bandas espectrais foram exportadas para ArcMap, por meio da ferramenta Add Data. Após o descarregamento das cenas, foi gerada no algorítimo Image Analysis>composite bands, a composição RGB filtro-banda, a melhor composição foi composta pelas bandas 3, 4 e 5 (Landsat 5, anos 2005 e 2010) e bandas 4,5 e 6 (Landsat 8, ano 2016). O quadro 1 caracteriza as aplicações, bandas e faixas espectrais utilizadas para a classificação das classes de uso e ocupação da terra.

Para a classificação do ano de 2016, foram utilizadas as bandas espectrais $4(0,64-0,67 \mu \mathrm{m}), 5(0,85$ $-0,88 \mu \mathrm{m})$ e $8(0,50-0,68 \mu \mathrm{m})$, referentes ao sensor espectral OLI (Operation Land Imager), além da banda $6(1,57-1,65,5 \mu \mathrm{m})$, captada pelo sensor SWIR1. As imagens pertecem ao satélite Landsat 8. As principais características e aplicações dessas bandas são similares às bandas 3,4 e 5 do Landsat 5, a principal diferença está na resolução espacial, que passa de 30 metros para 15 metros, após o fusionamento com banda pancromática.

Após a composição das bandas, foi adotado o Datum Horizontal WGS 1984 e o Sistema de Coordenadas Planas UTM, Zona 21 Sul. As imagens compostas foram equalizadas (realce e contraste) por meio do Image Analysis, nas funções Percent Clip e Histograma. Segundo Martins (2012, p. 29), "o ajustamento do histograma melhora o realce e o contraste das cenas, facilitando a diferenciação visual para o intérprete entre as diferentes formas de uso do solo e cobertura vegetal".

Para agrupamento das cenas 230/062 e 231/062, conforme a temporalidade estabelecida, as imagens foram mosaicadas com aplicação do algorítimo Mosaic To New Raster. Após esse procedimento, a função Clip foi aplicada para o recorte da área de estudo.

Quadro 1 - Principais características e aplicações das bandas 3, 4 e 5 do sensor TM do satélite Landsat- 5

\begin{tabular}{|c|c|c|}
\hline BANDA & $\begin{array}{l}\text { FAIXA } \\
\text { ESPECTRAL } \\
(\mu \mathrm{m})\end{array}$ & $\begin{array}{c}\text { PRINCIPAIS CARACTERISTICAS E APLICAÇÕES DAS BANDAS TM } \\
\text { DO SATÉLITE LANDSAT } 5\end{array}$ \\
\hline 3 & $(0,63-0,69)$ & $\begin{array}{l}\text { A vegetação verde, densa e uniforme, apresenta grande absorção, } \\
\text { ficando escura, permitindo bom contraste entre as áreas ocupadas com } \\
\text { vegetação (ex.: solo exposto, estradas e áreas urbanas). Apresenta } \\
\text { bom contraste entre diferentes tipos de cobertura vegetal (ex.: campo, } \\
\text { cerrado e floresta). Permite análise da variação litológica em regiões } \\
\text { com pouca cobertura vegetal. Permite o mapeamento da drenagem por } \\
\text { meio da visualização da mata galeria e entalhe dos cursos dos rios em } \\
\text { regiões com pouca cobertura vegetal. É a banda mais utilizada para } \\
\text { delimitar a mancha urbana, incluindo identificação de novos } \\
\text { loteamentos. Permite a identificação de áreas agrícolas. }\end{array}$ \\
\hline 4 & $(0,76-0,90)$ & $\begin{array}{l}\text { Os corpos de água absorvem muita energia nesta banda e ficam } \\
\text { escuros, permitindo o mapeamento da rede de drenagem e } \\
\text { delineamento de corpos de água. A vegetação verde, densa e uniforme, } \\
\text { reflete muita energia nesta banda, aparecendo bem clara nas imagens. } \\
\text { Apresenta sensibilidade à rugosidade da copa das florestas (dossel } \\
\text { florestal). Apresenta sensibilidade à morfologia do terreno, permitindo a } \\
\text { obtenção de informações sobre Geomorfologia, Solos e Geologia. } \\
\text { Serve para análise e mapeamento de feições geológicas e estruturais. } \\
\text { Serve para separar e mapear áreas ocupadas com pinus e eucalipto. } \\
\text { Serve para mapear áreas ocupadas com vegetação que foram } \\
\text { queimadas. Permite a visualização de áreas ocupadas com macrófitas } \\
\text { aquáticas (ex.: aguapé). Permite a identificação de áreas agrícolas. }\end{array}$ \\
\hline 5 & $(1,55-1,75)$ & $\begin{array}{l}\text { Apresenta sensibilidade ao teor de umidade das plantas, servindo para } \\
\text { observar estresse na vegetação, causado por desequilíbrio hídrico. Esta } \\
\text { banda sofre perturbações em caso de ocorrer excesso de chuva antes } \\
\text { da obtenção da cena pelo satélite. }\end{array}$ \\
\hline
\end{tabular}

Fonte - INPE, 2016

$\begin{array}{lllll}\text { Caminhos de Geografia } \quad \text { Uberlândia - MG } & \text { v. 21, n. 73 } \quad \text { Mar/2020 } & \text { p. 347-355 Página } 350\end{array}$


Evolução espaço-temporal do uso e cobertura da terra na Bacia do rio Puraquequara (Manaus-AM)
Renato Kennedy Ribeiro Neves leda Hortêncio Batista José Roselito Carmelo da Silva Elton Alves de Souza Filho Eduardo Papi Lemos das Neves

O levantamento do uso e ocupação da terra foi realizado por meio da "Classificação não Supervisionada", gerado pelo processamento automático de geração de classes (IBGE, 2013). Nesse procedimento, os recortes espaciais foram classificados pelos algoritmos Image Classification> Iso Cluster Unsupervised Classification.

Para o mapeamento, foram selecionadas as seguintes classes: águas continentais, vegetação primária, vegetação secundária, solo exposto e mancha urbana ( Quadro 2).

\section{RESULTADOS E DISCUSSÃO}

Analisando os resultados de uso e ocupação da terra (ilustrado na Tabela 13 e espacializado na Figura 2), numa temporalidade de 11 (onze) anos, observou-se que, no primeiro ano (2005), a classe de vegetação primária apresentou uma área de $562,76 \mathrm{~km}^{2}$ da área total da bacia hidrográfica do Rio Puraquequara. No ano de 2010, verificou-se a redução desta classe para $554,63 \mathrm{~km}^{2}$. Em 2016, novamente os resultados mostraram uma diminuição da classe para $546,34 \mathrm{~km}^{2}$. No intervalo de tempo estudado, houve um decréscimo de $16,42 \mathrm{Km}^{2}$ da vegetação original, fato que correspondeu uma tendência do avanço das classes de vegetação secundária, solo exposto e mancha urbana.

A classe de vegetação secundária ocupava, em 2005, uma área de $53,73 \mathrm{~km}^{2}$. No ano de 2010 , ocorreu um crescimento para $62,34 \mathrm{~km}^{2}$. Em 2016, a classe foi reduzida para $51,05 \mathrm{~km}^{2}$. O aumento em 2010 foi ocasionado pela supressão da vegetação primária, já em 2016, ocorreu uma conversão de áreas regeneradas para as classes de solo exposto e mancha urbana.

Quadro 2 - Classes de uso e ocupação da terra.

\begin{tabular}{|l|l|}
\hline \multicolumn{1}{|c|}{ CLASSE } & \multicolumn{1}{|c|}{ DESCRIÇÃo } \\
\hline Águas Continentais & $\begin{array}{l}\text { Incluem todos os recursos hídricos interiores, que } \\
\text { foram representados rio principal e seus tributários. }\end{array}$ \\
\hline Vegetação Primária & $\begin{array}{l}\text { Caracterizada como de máxima expressão local, com } \\
\text { grande diversidade biológica, sendo os efeitos das } \\
\text { ações antrópicas mínimos, a ponto de não afetar } \\
\text { significativamente suas características originais de } \\
\text { estrutura e de espécies. }\end{array}$ \\
\hline Vegetação Secundária & $\begin{array}{l}\text { Áreas que, após a supressão total da vegetação } \\
\text { florestal, encontram-se em processo avançado de } \\
\text { regeneração da vegetação arbustiva e/ou arbórea. }\end{array}$ \\
\hline Solo Exposto & $\begin{array}{l}\text { Áreas sem cobertura vegetal, oriundos de zonas de } \\
\text { exploração de madeira ou desenvolvimento de áreas } \\
\text { agrícolas, pecuária e mineração (extração de areia). }\end{array}$ \\
\hline Mancha Urbana & $\begin{array}{l}\text { Manchas urbanas decorrentes da concentração } \\
\text { populacional formadora de lugarejos, vilas ou cidades } \\
\text { que apresentam infraestrutura diferenciada da área } \\
\text { rural. }\end{array}$ \\
\hline
\end{tabular}

Fonte - Adaptado do "Manual Técnico de uso da Terra" (IBGE, 2013)

Tabela 1 - Quantitativo de área coberta $\left(\mathrm{Km}^{2}\right)$ e em percentual (\%) das classes de Uso e Cobertura da Terra na Bacia do Rio Puraquequara dos anos de 2005, 2010 e 2016.

\begin{tabular}{l|c|c|c|c|c|c}
\hline \multirow{2}{*}{ CLASSE } & \multicolumn{3}{|c}{$\mathbf{2 0 0 5}$} & \multicolumn{2}{c}{$\mathbf{2 0 1 0}$} & \multicolumn{2}{c}{$\mathbf{2 0 1 6}$} \\
\cline { 2 - 8 } & $\begin{array}{l}\text { ÁREA } \\
\left(\mathbf{K m}^{2}\right)\end{array}$ & $\%$ & $\begin{array}{c}\text { ÁREA } \\
\left(\mathbf{K m}^{2}\right)\end{array}$ & $\%$ & $\begin{array}{c}\text { ÁREA } \\
\left(\mathbf{K m}^{2} \mathbf{)}\right.\end{array}$ & $\%$ \\
\hline Vegetação primária & 562,76 & 81,15 & 554,63 & 79,89 & 546,34 & 78,78 \\
\hline Vegetação secundária & 53,73 & 7,74 & 62,34 & 8,99 & 51,05 & 7,36 \\
\hline Solo exposto & 48,61 & 7,01 & 43,16 & 6,22 & 77,85 & 11,23 \\
\hline Águas continentais & 26,64 & 3,82 & 29,4 & 4,23 & 9,62 & 1,38 \\
\hline Mancha urbana & 1,86 & 0,28 & 4,65 & 0,67 & 8,58 & 1,25 \\
\hline
\end{tabular}


Evolução espaço-temporal do uso e cobertura da terra na Bacia do rio Puraquequara (Manaus-AM)
Renato Kennedy Ribeiro Neves leda Hortêncio Batista José Roselito Carmelo da Silva Elton Alves de Souza Filho Eduardo Papi Lemos das Neves

O solo exposto apresentou a maior evolução espaço-temporal na bacia entre os anos de 2005 a 2016. A variação correspondeu $29,24 \mathrm{~km}^{2}$ de expansão da classe sobre as áreas de vegetação primária e secundária. As águas continentais ocuparam uma área de $26,64 \mathrm{~km}^{2} \mathrm{em} 2005$. Em comparação com 2016, houve uma redução espacial da classe possivelmente motivada por algumas alterações como a aplicação do processo de mosaicamento das cenas 230 e 231 para as duas primeiras temporalidades, além da possiblidade de distorções na imagem do ano de 2016. Segundo Silva et.al. (2012), as mudanças podem ser inerentes à plataforma, ao instrumento, ao tipo de sensor e ao modelo da Terra.

Figura 2- Mapa da evolução espaço-temporal do uso e cobertura da terra da Bacia do Rio Puraquequara, Manaus (AM).

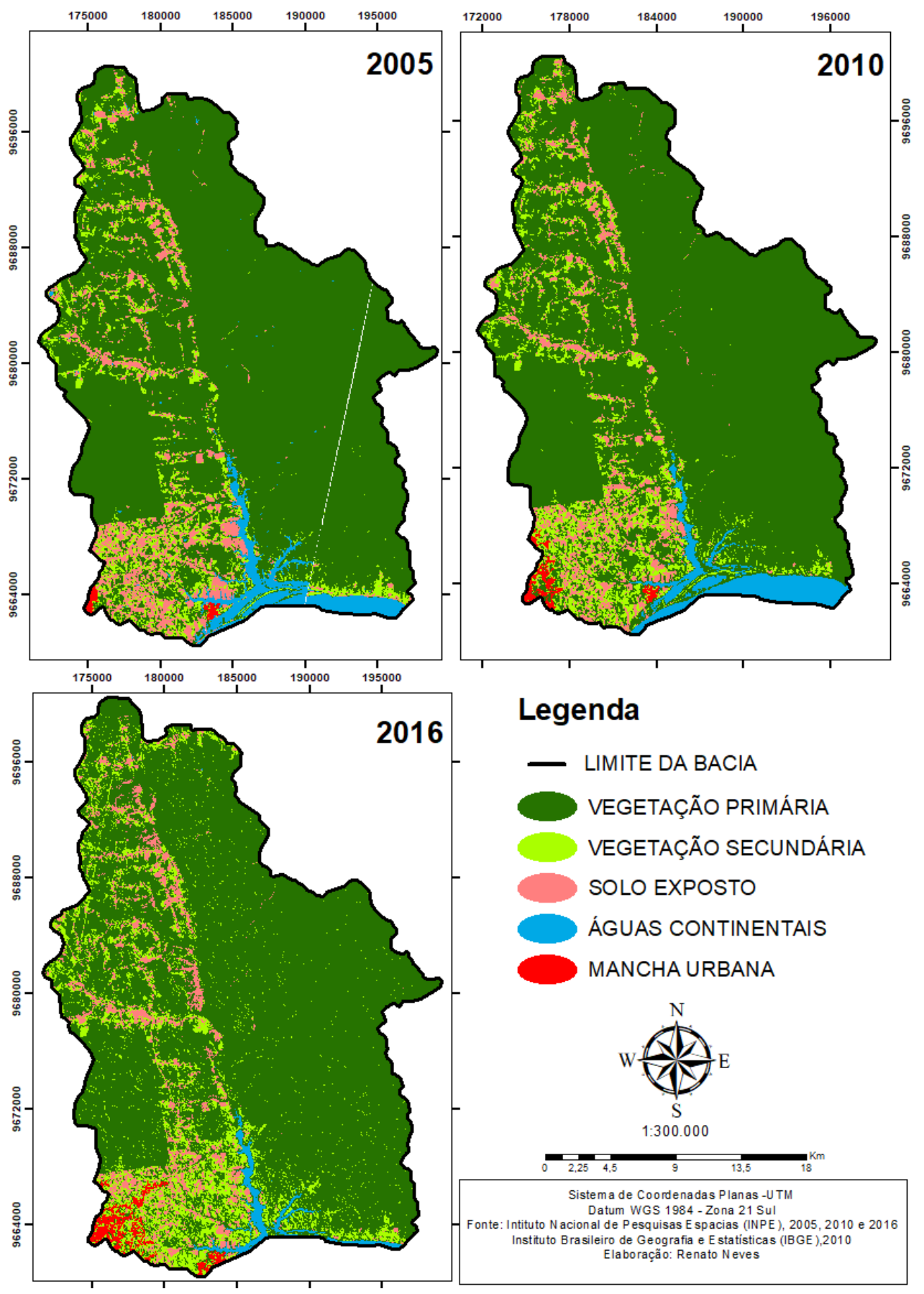

Fonte - Autores, 2018. 
A mancha urbana ocupou uma extensão territorial de 1,86 Km² em 2005. Entre 2010 e 2016, a classe avançou $6,73 \mathrm{~km}^{2}$ sobre as áreas de vegetação primária, secundária e solo exposto.

A evolução espaço-temporal do uso e cobertura da terra na bacia do Rio Puraquequara apresentou moderadas variações entre as classes. Na figura 3 estão descritas as taxas percentuais entres os anos avaliados.

Figura 3 - Comparação do Uso e Cobertura da Terra na Bacia do Rio Puraquequara entre 2005 a 2016.

Classes de uso e ocupação - (\%/ano)

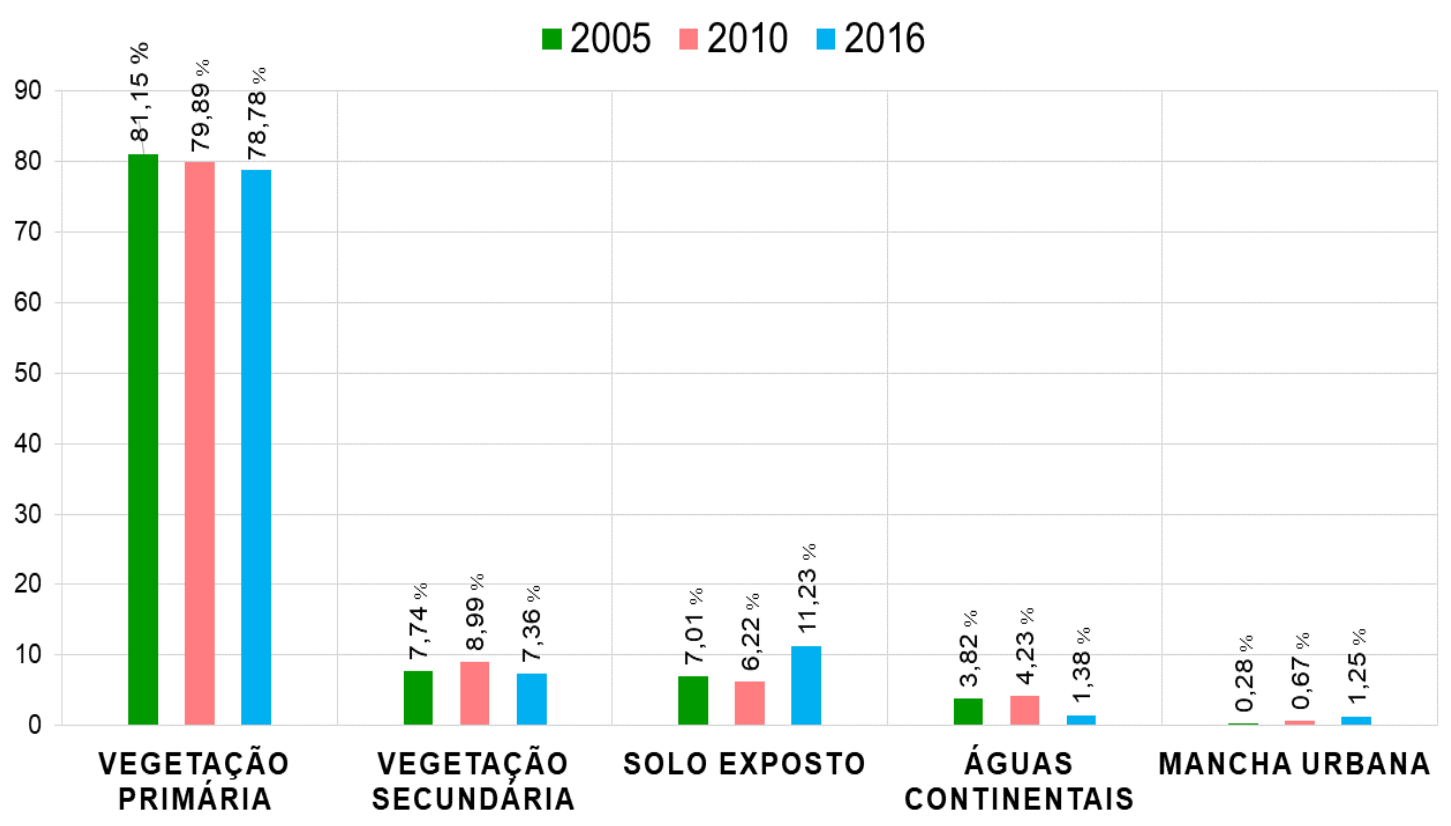

Fonte - Autores, 2018.

As mudanças observadas na Bacia Hidrográfica do Rio Puraquequara são mais densas na porção sudoeste. Nas observações de Fortes (2001), esse setor é o mais urbanizado e apresenta cobertura vegetal de forma pontual e descontínua, totalizando cerca $11 \mathrm{Km}^{2}$ de área verde. De acordo com a pesquisa, ficou evidente que há uma conversão de classes. O solo exposto, ampliado pelo desmatamento, contribuiu para expansão dos aglomerados subnormais, principalmente nos bairros limítrofes Distrito Industrial e Jorge Teixeira.

Os resultados de Pequeno Filho (2005) demostraram que a classe de mata primária, que neste trabalho é denominada de vegetação primária, representou um percentual de $61,48 \%$ e a classe de solo exposto $3,78 \%$. Esses resultados mostram as diferenças para as classes analisadas no mesmo período, vegetação primária $(81,15 \%)$ e solo exposto $(7,01 \%)$.

A explicação para as diferenças nos percentuais corresponde à metodologia utilizada pelo autor. No seu estudo, é estabelecido o critério de nove classes de uso e cobertura do solo, a área calculada da bacia foi de $687 \mathrm{Km}^{2}$, a imagem do satélite CBERS (com mais de 20 focos de nuvens), esses fatores ocasionam a redução da quantificação espacial das classes, mas fica evidente nos estudos do autor a predominância da vegetação natural na área.

No médio curso da bacia hidrográfica do Puraquequara, dois fatores são importantes para permanência da vegetação primária: a Reserva Florestal Adolpho Ducke, que por meio do decreto municipal 1.502, de 27 de março de 2012, foi declarada Área de Proteção Ambiental (APA) e as bases de instruções do Exército Brasileiro, presentes na margem esquerda. 


\section{CONCLUSÃO}

O presente trabalho buscou analisar por meio das imagens de satélites e do SIG a evolução espaçotemporal das classes temáticas predominantes na Bacia Hidrográfica do Rio Puraquequara. $O$ reconhecimento das formas de uso e cobertura da terra foi importante para identificar espacialmente os padrões das classes e suas evoluções acarretadas pela expansão de áreas urbanas e agrícolas.

Os resultados demostraram que a classe vegetação primária foi predominante na área de estudo o que contribui para manutenção dos serviços ambientais proporcionados pelo Bioma Amazônico as populações humanas.

O crescimento da macha urbana e da classe de solo exposto sobre as áreas verdes necessitam de mais atenção por parte do município, a criação de novas Áreas de Preservação Permanente (APP) é uma medida eficaz para tributários da margem direita do Rio Puraquequara. A fiscalização da Secretaria Municipal de Meio Ambiente e Sustentabilidade (SEMMAS) em conjunto com o Instituto Municipal de Planejamento Urbano (IMPLURB) deve ser mais ativa, principalmente na porção sudoeste da bacia, onde foi identificado o espraiamento dessas classes.

Portanto, o estudo desenvolvido, contribuirá para identificação e monitoramento de áreas afetadas pelo desmatamento ou supressão da vegetação e pela expansão das estruturas urbanas. Os dados levantados são teoricamente importantes para elaboração do Plano de bacia e, principalmente, para gestão e regulação dos recursos hídricos na bacia hidrográfica do Rio Puraquequara.

\section{REFERÊNCIAS}

ALBUQUERQUE, Adoréa Rebello da C.. Bacia Hidrográfica: unidade de planejamento ambiental. Revista Geonorte, Edição Especial, v.4, n.4, p.201 - 209, Manaus: UFAM, 2012. Disponível em: < periodicos.ufam.edu.br/revista-geonorte/article/viewfile/1913/1788 > Acesso: 07 nov. 2017.

BOTELHO, R.G.M. Bacias Hidrográficas Urbanas. in: Guerra, A.J.T. (Org.). Geomorfologia Urbana. Rio de Janeiro: Bertrand Brasil, 2011. p. 71-115.

BRASIL. Decreto Lei no 9.433, de 8 de janeiro de 1997. Da política nacional de recursos hídricos. Brasília, DF, 1997. Disponível em: < http://www.planalto.gov.br/ccivil_03/Leis/L9433.htm>

COSTA, E.B.S; SILVA, C.L; SILVA, M.L. Caracterização física de bacias hidrográficas na região de Manaus - AM. Revista Caminhos da Geografia (Online), v.14, n. 46, p. 93-100, jun. de 2013. Disponível em: < http://www.seer.ufu.br/index.php/caminhosdegeografia/article/view/19846> Acesso em: 15 de set. de 2018.

ESRI - Environmental Systems Research Institute. ArcGis Desktop 10.5. Version 10.5. 0. 6491: 2016.

FORTES, Mircia Ribeiro. Diagnóstico morfodinâmico aplicado ao planejamento ambiental da microbacia hidrográfica do rio Puraquequara. Manaus: UA/ICHL, 2001.

IBGE - INSTITUTO BRASILEIRO DE GEOGRAFIA E ESTATÍSTICA. Manual técnico de uso da terra. 3. ed. Rio de Janeiro: IBGE, 2013. Disponível em: < https://biblioteca.ibge.gov.br/visualizacao/livros/liv81615.pdf>

Manaus. 2010. 1 mapa Estado do Amazonas: Base Vetorial do Município de $\mathrm{ftp}: / /$ geoftp.ibge.gov.br/cartas e mapas/mapas para fins de levantamentos estatisticos/censo dem ografico 2010/mapas municipais estatisticos/am/> Acesso em: junho de 2017.

Aglomerados Subnormais. Rio de Janeiro: IBGE, 2010. Disponível em: $<$ https://ww2.ibge.gov.br/home/presidencia/noticias/imprensa/ppts/0000001516481120201348010574 8802.pdf> Acesso: 22 de mar. 2019. 
INPE - INSTITUTO NACIONAL DE PESQUISAS ESPACIAIS. Imagem Landsat 5: órbitas 230/231; ponto 062. Divisão de geração de imagens: 2005. < www.dgi.inpe.br> Acesso: 18 de dez. 2016.

Imagem Landsat 5: órbitas 230/231; ponto 062. Divisão de geração de imagens: 2010. < www.dgi.inpe.br> Acesso: 18 de dez. 2016.

Imagem Landsat 8: órbita 231, ponto 062. Divisão de geração de imagens: 2016. < www.dgi.inpe.br> Acesso: 18 de dez. 2016.

MARTINS, Marcos Henrique Brainer. Dinâmica do uso e cobertura da terra com a utilização de geotecnologias: estudo na área de proteção ambiental da margem direita do Rio Negro, setor Paduari-Solimões. Manaus: UFAM, 2012. Dissertação de Mestrado.

MIRANDA, Michel Jader de Oliveira. $O$ uso de geotecnologias na análise temporal do processo de expansão urbana sobre a bacia hidrográfica do Puraquequara. Tese (Mestrado em Geografia) - Manaus: UFAM, 2017.

PEQUENO FILHO, Antônio da Mata. Sensoriamento remoto e SIG na análise ambiental da microbacia do Rio Puraquequara Manaus, AM - Brasil. Tese (Mestrado em de Ciências do Ambiente). Manaus: UFAM, 2005.

PROJETO GEO CIDADES. Relatório ambiental urbano integrado: informe GEO. Rio de Janeiro: Consórcio Parceria 21, 2002. Q'

SILVA, B.S; LEOBMANN, D.G.S.N; FOLHARINI, S.O; NOGUEIRA, S.F; VICENTE, L.E; ANDRADE, R.G; FURTADO, A.L.S. Procedimentos para correção geométrica de imagens de satélites. EMBRAPA: São Paulo, 2012. Disponível em:< https://www.embrapa.br/busca-de-publicacoes//publicacao/958866/procedimentos-para-correcao-geometrica-de-imagens-de-satelite> Acesso em: 14 de jan. de 2018.

SILVA, J. R. C. Impactos ambientais da exploração de areia na microbacia do igarapé do Mariano no município de Manaus-AM. Jundiaí: Paco Editorial, 2016.

SOARES, Leonardo Silva. Planejamento ambiental integrado: subsídios para o desenvolvimento sustentável das sub-bacias hidrográficas do baixo curso do rio Itapecuru, Maranhão. Tese (Doutorado em Desenvolvimento e Meio Ambiente) - Teresina: UFPI, 2016.

Recebido em: 08/05/2019

Aceito para publicação em: 02/07/2019 